\title{
Renewable Power Generation by Reverse Electrodialysis Using an Ion Exchange Membrane
}

\author{
Sourayon Chanda and Peichun Amy Tsai *(D) \\ Department of Mechanical Engineering, University of Alberta, 9211116 St. NW, \\ Edmonton, AB T6G 1H9, Canada; sourayon@ualberta.ca \\ * Correspondence: peichun.amy.tsai@ualberta.ca
}

Citation: Chanda, S.; Tsai, P.A. Renewable Power Generation by Reverse Electrodialysis Using an Ion Exchange Membrane. Membranes 2021, 11, 830. https://doi.org/ $10.3390 /$ membranes11110830

Academic Editors: Hanki Kim, Ji-Yeon Choi and Seung-Cheol Yang

Received: 30 September 2021

Accepted: 22 October 2021

Published: 28 October 2021

Publisher's Note: MDPI stays neutral with regard to jurisdictional claims in published maps and institutional affiliations.

Copyright: (c) 2021 by the authors. Licensee MDPI, Basel, Switzerland. This article is an open access article distributed under the terms and conditions of the Creative Commons Attribution (CC BY) license (https:// creativecommons.org/licenses/by/ $4.0 /)$.

\begin{abstract}
Reverse electrodialysis (RED) is a promising technology to extract sustainable salinity gradient energy. However, the RED technology has not reached its full potential due to membrane efficiency and fouling and the complex interplay between ionic flows and fluidic configurations. We investigate renewable power generation by harnessing salinity gradient energy during reverse electrodialysis using a lab-scaled fluidic cell, consisting of two reservoirs separated by a nanoporous ion exchange membrane, under various flow rates $\left(q_{f}\right)$ and salt-concentration difference $(\Delta c)$. The current-voltage $(I-V)$ characteristics of the single RED unit reveals a linear dependence, similar to an electrochemical cell. The experimental results show that the change of inflow velocity has an insignificant impact on the $I-V$ data for a wide range of flow rates explored $(0.01-1 \mathrm{~mL} / \mathrm{min})$, corresponding to a low-Peclet number regime. Both the maximum RED power density $\left(P_{c, m}\right)$ and open-circuit voltage $\left(\phi_{0}\right)$ increase with increasing $\Delta c$. On the one hand, the RED cell's internal resistance $\left(R_{c}\right)$ empirically reveals a power-law dependence of $R_{c} \propto \Delta c^{-\alpha}$. On the other hand, the open-circuit voltage shows a logarithmic relationship of $\phi_{0}=B \ln \Delta c+\beta$. These experimental results are consistent with those by a nonlinear numerical simulation considering a single charged nanochannel, suggesting that parallelization of charged nano-capillaries might be a good upscaling model for a nanoporous membrane for RED applications.
\end{abstract}

Keywords: renewable energy; reverse electrodialysis; ion-exchange membrane

\section{Introduction}

Salinity gradient energy (SGE) is a promising and abundant source of renewable energy harnessed by utilizing the chemical potential difference between freshwater and seawater. SGE can be captured using several technologies [1,2], such as reverse electrodialysis (RED) [3], pressure-retarded osmosis [4], and electric double layer capacitor [5]. Among these methods, RED has been an attractive, pollution-free alternative to harness the Gibbs free energy of mixing of electrolyte solutions [6]. A typical large-scale RED setup consists of a stack of fluidic cells with alternating cation- and anion-exchange membranes, whereby alternating dilute and concentrate salt solutions flow to generate ionic fluxes and, hence, renewable energy output across the electrodes at the two ends of the setup [6]. The RED technology could extract a power amounting to $2.24 \mathrm{MW}$ when $1 \mathrm{~m}^{3}$ of freshwater is mixed with seawater [7], thereby potentially producing a sustainable power output of $\approx 2.6 \mathrm{TW}$ [8] estimated with a global freshwater flow-rate of $\approx 1.2 \times 10^{6} \mathrm{~m}^{3} / \mathrm{s}$ [9].

The first experimental concept of RED was developed by Pattle (in the 1950s), using alternating chambers of fresh and saline water separated by acidic and basic membranes [10]. However, not until recently have there been active theoretical, numerical, and experimental investigations aiming at pilot projects [11,12], efficient membrane materials [13-22], improved large-scale cell designs [22-28], and better understanding of the underlying mechanisms at pore-scale charged interfaces [29-31] for optimal power outputs $[1,17,32,33]$. However, it is challenging to carry out rigorous theoretical and numerical analyses to fully 
compute and accurately predict the electric outputs of a RED system. The challenges stem from the coupled, nonlinear equations (of ion concentration, electric potential, flow velocity fields) as well as the complex effects of electrokinetics and ion concentration polarization involving charged nanochannels or nanoporous membranes [34-37].

Rigorous theoretical RED studies usually comprise simplified models of charged "capillary" membranes, using a single charged nanochannel to represent a typical (ionexchange) membrane pore [38,39]. With 1D (Poisson-Boltzmann) linearization of ionic concentrations, the analytical results show that the ratio of nanopore or nanochannel radius $(R)$ to the Debye length $\left(\lambda_{D}\right)$ plays a crucial role in determining membrane potential. More specifically, the maximal RED conversion efficiency decreases significantly by increasing the $R / \lambda_{D}$ from 0.1 to 10 . These findings critically imply that the size and charges of charged nano-pores/channels and electrolyte concentrations, which affect $\lambda_{D}$, influence the RED efficiency and electric potential generated. On the numerical front, the electrical responses of a single charged nanopore in two-dimensional micro/nano-junctions have been investigated without external flow [40,41], with an external flow of electrolytes [42], and for inhomogeneous surface charge [43]. These studies reveal optimal nanochannel length varying with ion concentrations $[40,41]$, a crucial role of nanochannel height on power output density and ion transfer [42], as well as the dependence of logarithmic current on the ratio of nanochannel length to height [43], respectively.

To elucidate pore-scale observations and understanding, as a bottom-up approach, researchers have recently investigated micro/nano-fluidic RED processes to measure $I-V$ characteristics of a single straight [44] or an array of charged nanochannels [16,36,45-47] between two microfluidic reservoirs under $\Delta c$. The studies of conical nanochannels have also attracted much research endeavor recently due to the intriguing nonlinear $I-V$ response of ionic current rectification for biomedical applications [48-51]. Directly addressing RED applications, a single-pore (polyimide) membrane system under $\Delta c$ (using $\mathrm{KCl}$ solutions ranging from 1 to $1000 \mathrm{mM}$ ) was fabricated that could generate a power output of $\approx 26 \mathrm{pW}$ and estimated to upscale the power density by $\approx 1000 \times$ with parallelism $[29,52,53]$. Besides, a membrane-less RED cell design with closely-packed nanoparticles reported a greater power output of the order of magnitude of $\mathrm{nW}[20,54,55]$.

To optimize large-scale implementation of RED or blue energy technology using membranes, as a top-down approach, multiple compartment RED cells have been constructed $[28,56,57]$. Recent studies have shown several crucial influences of ion-exchange membranes [3,58,59] of different materials (e.g., microfiltration [60], polymeric [15,61,62], graphene $[18,20]$, Nafion $[13,63])$, surface charges, and pore-size distributions, electrolyte solutions (e.g., types of ions [64-66], multivalent ions [67], ion concentrations), as well as hydrodynamics affected by the flow configurations [68] and cell designs through separators' dimensions [23-26]. Typical power density outputs measured with various ion exchange membrane stacks ranged from 0.13 to $2.48 \mathrm{~W} \mathrm{~m}^{-2}$ [32].

Because of complex variations of RED components, electrical measurements done with various RED systems could not be comparatively compared with each other directly $[69,70]$. Moreover, electric measurements and resultant power density conducted with microscopic charged nano-channels or pores can differ significantly from those by the RED stackmembrane systems by several orders of magnitude. This discrepancy implies that a proper upscaling model from microscopic nanochannels to macroscopic RED stacks is missing and remains challenging [32,69-72]. In this study, we hence developed a convenient mesoscale experimental platform (of a single compartment) to systematically investigate the steadystate electrical characteristics of an ion-exchange membrane under several vital parameters. In particular, we used a commercially available Nafion membrane, which is also commonly used for generating fuel cell renewable energy. We measured the Nafion's internal resistance, open-circuit, and power output density under different salt concentrations and external flow rates, while the latter influence is hardly explored in the literature. The fluidic platform made with additive manufacturing can be extended to systematically investigate the optimal operating conditions for other membranes under various crucial parameters, 
e.g., $\Delta c$, ion types, external flows, and separation gaps, facilitating systematic electrical measurements and comparisons between different ion-exchange membranes.

\section{Materials and Methods}

Figure 1a illustrates our RED renewable power generation unit, consisting of two reservoirs separated by a cation exchange membrane. A steady-state flow condition of solutions at different concentrations is maintained across the membrane. A concentration difference is hence generated across the membrane and acts as a driving force. The membrane, however, allows only the cations to flow across to the other side, thus creating an ionic flow across the membrane. This ionic flow, in turn, is harnessed using electrodes at the two-side ends of reservoirs. The fluidic cell was cylindrical with a diameter of $40 \mathrm{~mm}$ and contained two internal chambers for the passage of high and low concentration solutions, respectively. The diameter and height of each inner cylindrical section were 25 $\mathrm{mm}$ and $12.5 \mathrm{~mm}$, respectively. The fluidic cell was fabricated with a 3D printer (Form 2) using stereo-lithography. A syringe pump was used to inject salt solutions of different concentrations through the two reservoirs at a particular flow rate.

The salt solution was made by dissolving various amounts of sodium chloride $(\mathrm{NaCl})$ in deionized water. The lowest concentration solution used is deionized water, without any salt added to maximize the electrical output. The cation-exchange membrane (CEM) used is a commercially available Nafion membrane, which is also used for fuel cell research and applications. The membrane has a typical thickness of $127 \mu \mathrm{m}$, a conductivity of $0.1 \mathrm{~S} / \mathrm{cm}$ [73], a tensile modulus of $114 \mathrm{MPa}$ (water-soaked, at $23^{\circ} \mathrm{C}$ ), the water content of $5 \%$, and a water update of $38 \%$ (Nafion $^{\mathrm{TM}} 115$, The Fuel Cell Store). The Nafion nanopores varied in shapes and sizes and were observed under a scanning electron microscope (SEM) to find an approximate pore-diameter to be $20-25 \mathrm{~nm}$, as shown in Figure 2. The average pore size is comparable to the Debye length of $\mathrm{O}(10 \mathrm{~nm})$ with $\mathrm{NaCl}$ concentration of 1 $\mathrm{mM}$. The cross-sectional diameter of the membrane held by the fluidic assembly is $17 \mathrm{~mm}$, corresponding to a cross-sectional area of $A_{c}=227 \mathrm{~mm}^{2}$.
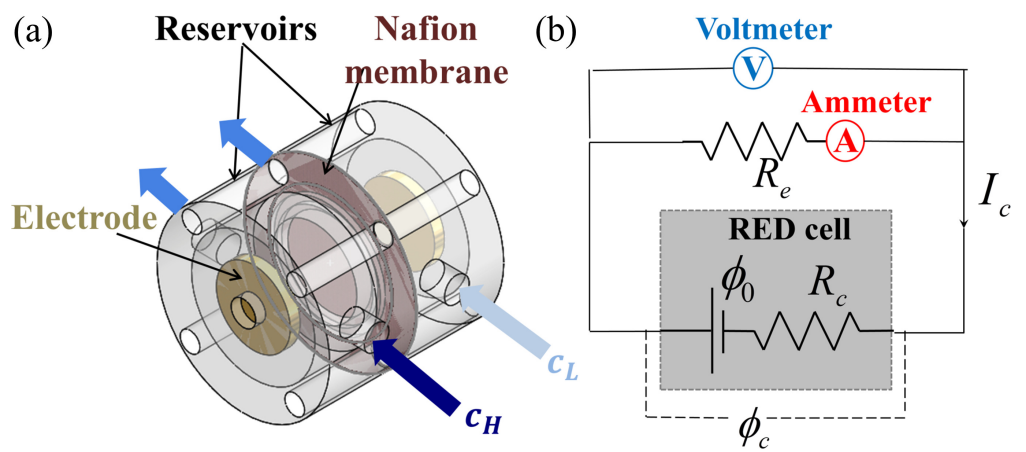

Figure 1. (a) Schematic diagram and (b) the equivalent electrical circuit of the reverse electrodialysis (RED) cell, comprised of two reservoirs separated by a cation-selective Nafion membrane. Solutions of different salt concentrations $\left(c_{H}\right.$ and $c_{L}$ ) flow through the reservoirs. When connecting an external circuit to the two side-electrodes, we obtain the open-circuit voltage $\left(\phi_{0}\right)$ and internal resistance $\left(R_{c}\right)$ of the RED cell under a constant flow rate, by measuring the operating voltage $\left(\phi_{c}\right)$ and current $\left(I_{c}\right)$ with a voltmeter and ammeter, respectively, while varying the external resistance $\left(R_{e}\right)$ connected. 
(a)

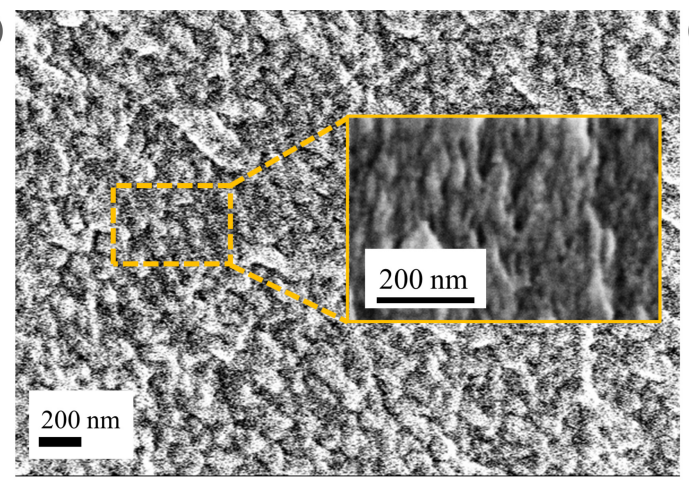

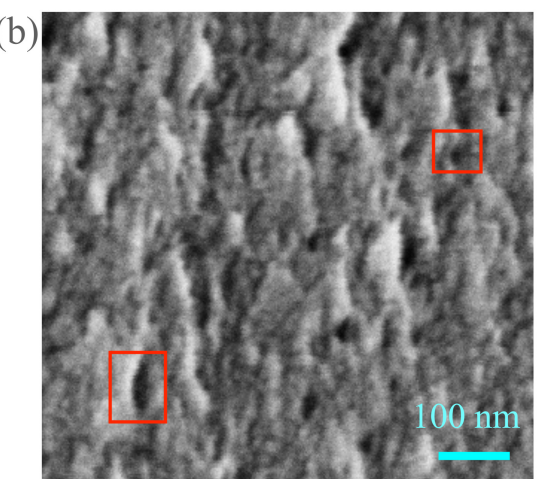

Figure 2. (a) Representative SEM image of the Nafion membrane used with approximate nanopore diameter of 20-25 nm. The nanopore size distribution is analyzed with ImageJ image analysis of high-resolution SEM images, such as (b). As illustrated, a couple of red boxes in (b) enclose typical nanopores, which are many and appear to be black in (b).

When electrolyte solutions with a salt-concentration difference flow across the CEM, the RED cell-assembly (Figure 1a) acts like a miniature battery with an electric potential $\left(\phi_{0}\right)$ and internal resistance $\left(R_{c}\right)$, as depicted in Figure $1 \mathrm{~b} . \phi_{0}$ is known as the open-circuit voltage, i.e., the voltage output when no current flows through the electrical circuit. When connected to an external resistance $\left(R_{e}\right)$, the voltage supplied by the RED cell is $\phi_{c}$ with an electric current, $I_{c}$. A voltmeter (Keithley 2450 Sourcemeter) and an ammeter (DigiKey $2831 \mathrm{E}$ ) were used for electrical measurements of $\phi_{c}$ and $I_{\mathcal{c}}$, respectively, while a variable resistance was used to control the external resistance, $R_{e}$. We used ten different values of $R_{e}$ between $20 \mathrm{k}-700 \mathrm{k}$ and the current $\left(I_{\mathcal{c}}\right)$ and voltage $\left(\phi_{c}\right)$ readings were recorded at $15 \mathrm{~Hz}$ for one minute. The $I-V$ characteristics of the RED cell were obtained from the time-averaged values of $I_{c}$ and $\phi_{c}$, reaching a steady-state.

Based on the electrical circuit diagram (see Figure 1b), the $I-V$ relation can be mathematically described as: $\phi_{c}=\phi_{0}-I_{c} R_{c}$. Using this equation, both $\phi_{0}$ and $R_{c}$ of the single-compartment RED cell can be calculated with a best linear-fit of the $I-V$ measurements (i.e., $\phi_{c}$ and $I_{c}$ data) from the y-intercept and the slope, respectively. One can also express $\phi_{c}$ using the external resistance $\left(R_{e}\right): \phi_{c}=I_{c} R_{e}$. Using the above two relations, the RED power output $P_{c}^{\prime}\left(=\phi_{c} I_{c}\right)$ can be obtained via the internal and external resistances via:

$$
P_{c}^{\prime}=\phi_{0}^{2} \frac{R_{e}}{\left(R_{e}+R_{c}\right)^{2}} .
$$

By optimization, the RED power output, $P_{c}^{\prime}$, has a maximum when the operating voltage is equal to the half of the open circuit voltage: $\phi_{c}=\phi_{0} / 2$, and can be estimated via:

$$
P_{c, m}^{\prime}=\phi_{0}^{2} /\left(4 R_{c}\right) \text {. }
$$

The maximum power output density, $P_{c, m}$, is the maximum power output $\left(P_{c, m}^{\prime}\right)$ per unit cross-sectional area of the membrane $\left(A_{c}\right)$. We analyzed the effects of $\Delta c$ and flow rate on the electrical outputs and power density of the RED cell. We further compared our experimental data with numerical results of the RED electrical characteristics using a single charged nanochannel [42].

\section{Results and Discussions}

\subsection{Influence of External Flow Rates}

Revealed in Figure 3 a are the typical $I-V$ measurements obtained for the RED cell under different flow rates, $q_{f}$. In the range of flow rates investigated $(10-1000 \mu \mathrm{L} / \mathrm{min})$, voltage $\phi_{c}$ has an inverse linear dependence on $I_{c}$, showing a constant internal resistance $\left(R_{c}=-d V / d I\right)$ of the RED cell. The general $I-V$ trends in Figure 3 a reveal a linear decrease 
of $\phi_{c}$ with increasing $I_{c}$ since $\phi_{c}=\phi_{0}-I_{c} R_{c}$ and both $\phi_{0}$ and $R_{c}$ remain nearly constant for a particular RED setup with specified solution concentrations. Furthermore, as revealed by Figure $3 a$, the I-V response does not vary significantly with the change in the flow rate of the solutions. The power output density $\left(P_{c}\right)$ from our setup can be found out from the $I-V$ data using the relation: $P_{c}=I_{c} \phi_{c} / A_{c}$, where $A_{c}$ is the membrane cross-sectional area confined by the fluidic assembly. Figure $3 b$ shows the results of the power output density, $P_{c}$, for various $q_{f}$. In good agreement with Equation (2), the maximum power output density is always observed when $\phi_{c}=\phi_{0} / 2$ for all the cases.
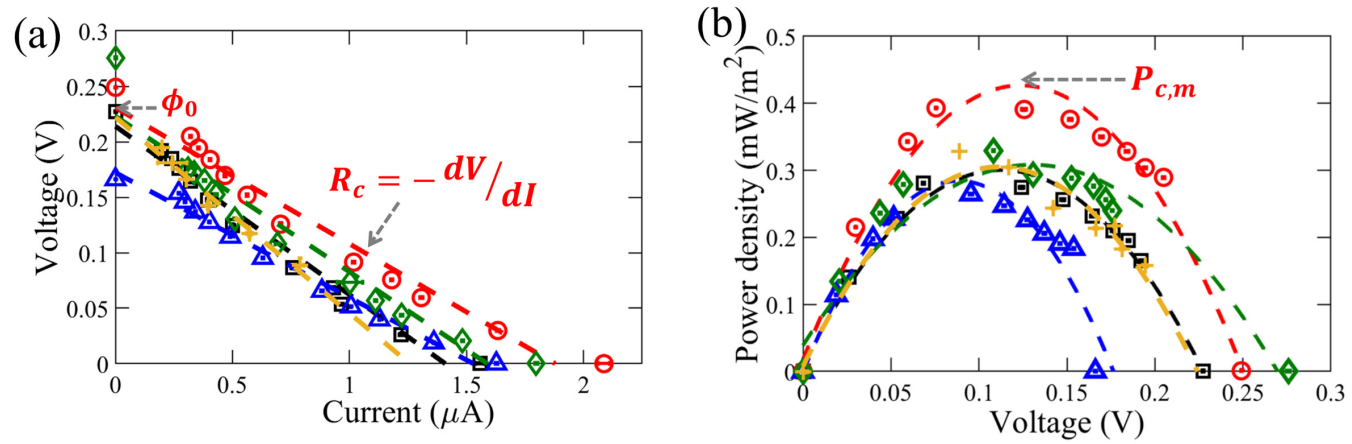

Figure 3. (a) Typical measurements of current-voltage $\left(I-V\right.$ or $\left.\phi_{c}-I_{\mathcal{c}}\right)$ and (b) the corresponding power density at different voltages of the RED cell using a Nafion membrane. Measurements of the open-circuit voltage $\left(\phi_{0}\right)$ and membrane internal resistance $\left(R_{c}=-d V / d I\right)$ are obtained from the $\mathrm{y}$ intercept and slope of the best linear fit of the $I-V$ curve, respectively. The greatest value of the power density curve in (b) denotes the maximum power density, $P_{c, m}$. Here, each set of the experiments are ran at different flow rates, $q_{f}=10$ (black square, $\square$ ), 100 (red circle, $\bigcirc$ ), 500 (blue triangle, $\triangle$ ), 750 (green diamond, $\diamond$ ), and 1000 (yellow plus, + ) $\mu \mathrm{L} / \mathrm{min}$, but with a constant salt-concentration difference of $\Delta c=0.86 \mathrm{M}$. The best linear fitting results of $R_{c}=-d V / d I$ for various $q_{f}$ are shown by the dashed lines in (a), with the same color as the corresponding data set. Similarly, the best quadratic fitting results of the power density, $P_{c}=P_{c}^{\prime} / A_{c}=\phi_{c} I_{c} / A_{c}$, varying with $\phi_{c}$ for various $q_{f}$ are shown in (b) by the dashed lines (with the matching color as the data set in (a)), revealing that the maximum power density $\left(P_{c, m}\right)$ occurs at $\phi_{c} \approx \phi_{0} / 2$.

We experimentally investigated the influence of flow rates on the RED electrical and power outputs. For each flow rate, at least three experiments were conducted to obtain the error bars reported based on the standard deviation, while keeping the concentration difference constant $(\Delta c=0.86 \mathrm{M})$. As illustrated by Figure 4 , the internal resistance of RED cell, open-circuit voltage, and maximum power density demonstrated a slight variation with changes in the inflow rate. The average maximum power output density, $P_{c, m}$, was found to be around $0.5 \mathrm{~mW} / \mathrm{m}^{2}$. The average values of internal resistance $\left(R_{c}\right)$ and opencircuit voltage $\left(\phi_{0}\right)$ were calculated to be $0.14 \mathrm{M} \Omega$ and $0.23 \mathrm{~V}$, respectively.
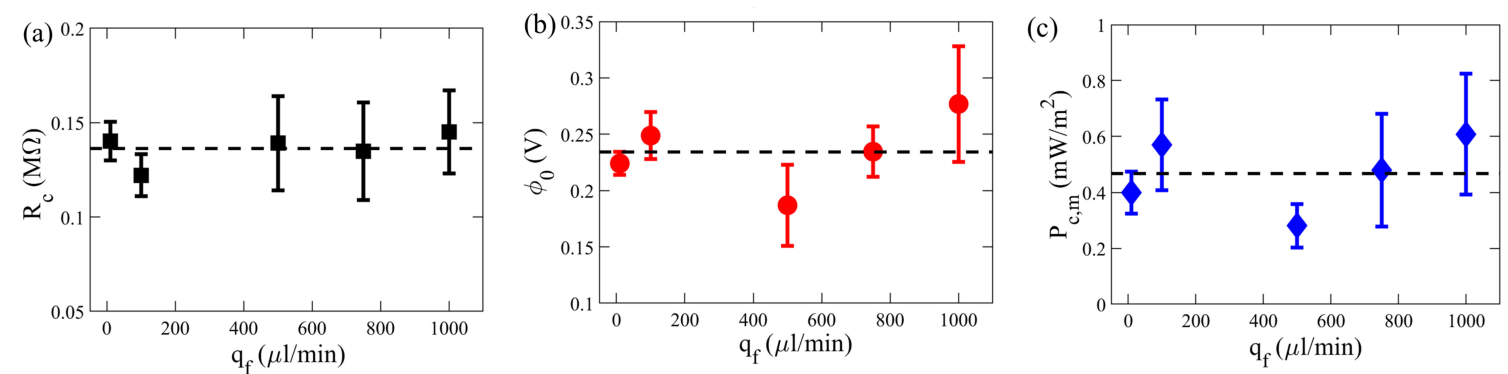

Figure 4. Insignificant variations of (a) internal resistance, $R_{c},(\mathbf{b})$ open-circuit voltage, $\phi_{0}$, and (c) maximum power output density at $\Delta c=0.86 \mathrm{M}$ under a wide range of flow rate, $q_{f}$. The dashed lines in (a-c) represent the average value of $R_{c}, \phi_{0}$ and $P_{c, m}$, respectively. 
In the experiments, we explored different flow rates over three orders of magnitude, ranging from 10 to $1000 \mu \mathrm{L} / \mathrm{min}$. We found that a higher flow rate above $1 \mathrm{~mL} / \mathrm{min}$ is too fast to achieve a complete set of steady-state electrical $I-V$ measurements for our setup. Therefore, the flow range explored corresponds to a low Peclet number regime, where the ratio of advective to diffusive transport rate is small. Here, we estimate $P e=v_{f} h / D$, with the flow velocity, $v_{f}$, a characteristic length scale for the RED processes, $h$, which could be approximated with the membrane thickness or dimension of the nanopores, and ion diffusion coefficient, $D$. When approximating $h$ with the nanopore dimension or membrane thickness, the corresponding Peclet number ranges between $10^{-9}$ and $10^{-5}$ for our setup, where diffusion is expected to dominate over advection.

\subsection{Effect of Concentration Difference}

We further carried out a systematic study of a wide range of concentration difference $\Delta c\left(=c_{H}-c_{L}\right)$, ranging from $0.51 \mathrm{mM}$ to $1.71 \mathrm{mM}$. For the electrical measurements, we kept the salt concentration of the dilute solute fixed $\left(c_{L} \approx 0\right)$, while the molarity of the concentrated solution was varied. The flow rate was kept constant at $1000 \mu \mathrm{L} / \mathrm{min}$ for studying the effect of $\Delta c$. We carried out investigations with five different values of $\Delta c$. For each $\Delta c$, at least three independent experiments were performed. Figure 5 demonstrates the effect of $\Delta c$ on the electrical characteristics, namely internal resistance, open-circuit voltage, and maximum power density, of the RED cell using a Nafion membrane.
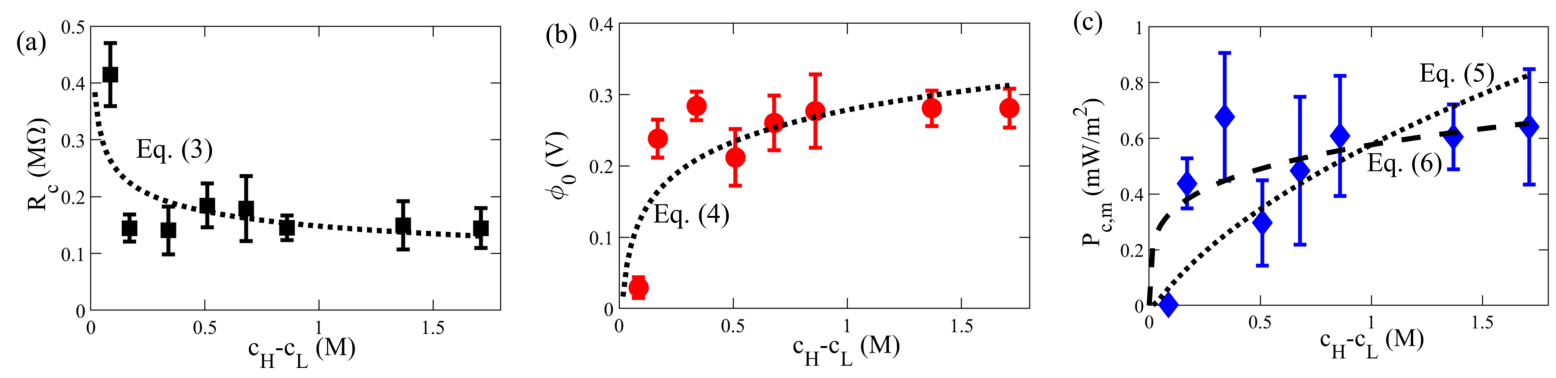

Figure 5. Variation of (a) internal resistance, $R_{c},(\mathbf{b})$ open-circuit voltage, $\phi_{0}$, and (c) maximum power output density, $P_{c, m}$, at $q_{f}=1000 \mu \mathrm{L} / \mathrm{min}$ for various concentration difference, $\Delta c\left(=c_{H}-c_{L}\right)$. The dotted lines in (a-c) represent Equations (4) and (5), respectively. The dashed line in (c) demonstrates the curve-fit using the simplified relation (6).

Shown in Figure 5a is the measurement of nanochannel internal resistance, $R_{c}$, under different $\Delta c$. When $\Delta c \gtrsim 0.2, R_{c}$ is nearly constant, with little variation with $\Delta c$. Besides, we observed a power-law dependence of the internal resistance on the concentration difference. In comparison, an empirical power-law relation between $R_{c}$ and $\Delta c$ was previously reported, with a 2D numerical simulation for a single charged nanochannel RED cell [42]:

$$
R_{c}=A \Delta c^{-\alpha},
$$

where $A$ and $\alpha$ are constants independent of $\Delta c$ but could depend on other factors. In the numerical model compared [42], coupled, nonlinear equations, based on the Poisson equation and the conservation of mass, momentum, and charged species (i.e., the continuity, Navier-Stokes, and Nerst-Planck equations, respectively) are simulated to obtain electrical potential, flow velocity, ionic concentrations, and hence the resultant electrical outputs. Although different configurations of charged interfaces are used here, our case of the RED experiment using the Nafion nano-porous membrane shows such a power-law relation of $R_{c}$, given in Equation (3), with the pre-factor 0.15 and the power-law scaling $\alpha=0.23$.

The error bars in both Figures 4 and 5 are obtained from 3-5 independent sets of experiments, showing $\approx 15 \%$ and $25 \%$ on average, respectively. Although the raw electrical $I-V$ data such as Figure 3 reveals stable and steady-state values, each independent experiment may still exhibit some reasonable variation due to external flow and curve fittings to obtain the final overall RED outputs. 


\subsection{Comparison with Numerical Results}

To explain the above power-law relation observed for our experimental membrane cell, one could approximate the nano-porous CEM membrane as bundle of charged nanochannels parallel to each other. To a first order approximation, for $N$ number of parallel nano-channels (each with internal electrical resistance $R_{i}$ ) the effective electric resistance $R_{\text {eff }}$ could be estimated as $N$ numbers of electrical resistors in parallel and, hence, $1 / R_{\text {eff }}=$ $\sum_{i}^{N} 1 / R_{i}$, i.e., $R_{\text {eff }} \approx A \Delta c^{-\alpha} / N$, also exhibiting a power-law relation.

Shown in Figure $5 b$ in our further experimental investigation of the dependence of the open-circuit voltage, $\phi_{0}$, on $\Delta c$, revealing a logarithmic dependence. The general trend shows that $\phi_{0}$ is increased with $\Delta c$, as a larger Gibbs free energy of mixing is available to harness electricity. Intriguingly, such a logarithmic relation was also reported by the numerical simulation of a single charged nanochannel RED between the two reservoirs, with the following expression [42]:

$$
\phi_{0}=B \ln \Delta c+\beta,
$$

where $B$ and $\beta$ are constants independent of $\Delta c$ but may depend on other parameters, such as membrane type and geometry, which were not explored in the simulation [42].

Fitting our data with the logarithmic relation of Equation (4), we found the best fitting results of $B=0.065$ and $\beta=0.28$, based on a least-square residual fitting method. Our experimental data shows that $\phi_{0}$ can be approximated to a constant for a sufficiently large $\Delta c$, which is consistent with the logarithmic relation of Equation (4) since $\phi_{0} \approx \beta$ for large $\Delta c$.

Figure $5 c$ reveals how the maximum output power density, $P_{c, m}$, varies with $\Delta c$. Despite scattering of the data, the general trends can be consistently described by the above empirical relations found for $R_{c}$ and $\phi_{0}$ varying with $\Delta c$. Using Equations (3) and (4), one can obtain an empirical relation for $P_{c, m}$ from Equation (2) [42]:

$$
P_{c, m}=\frac{\phi_{0}^{2}}{4 R_{c}} \frac{1}{A_{c}}=\frac{(B \ln \Delta c+\beta)^{2}}{4 A \Delta c^{-\alpha}} \frac{1}{A_{c}}
$$

where $\alpha$ is the same theoretical exponent as in Equation (3).

Consistently, our experimental data of $P_{c, m}$ shown in Figure $5 c$ yields the best fitting result of $\alpha \approx 0.26$. Considering the approximation $\phi_{0} \approx \beta$, this equation can be further simplified to:

$$
P_{c, m} \approx C \Delta c^{\alpha} / A_{c},
$$

where $C\left(=\beta^{2} / 4 A\right)=0.131$. The maximum power output density, $P_{c, m}$, was observed to remain in the range of 0.4 to $0.6 \mathrm{~mW} / \mathrm{m}^{2}$ with change in $\Delta c$ between 0.51 and $1.71 \mathrm{mM}$. In comparison, other experiments have reported a power density, $P_{c, m} \approx 0.5 \mathrm{~W} / \mathrm{m}^{2}$, using 10 units of commercial ion-exchange membranes, such as Ralex, Neosepta, and Fujifilm (e.g., Figure 4 by Vermaas et al. [67]), and a maximum power output $P_{c, m}^{\prime} \approx 1 \mu \mathrm{W}$ (e.g., Figure 10 by Chein et al. [74]) from a single cell RED design using a charged alumina membrane under $c_{H} / c_{L}=1000$ with $c_{L}=10^{-4} \mathrm{M}$. In addition, the typical power density output using a stack of membranes was found in the range of $\mathrm{O}(0.1-1) \mathrm{W} / \mathrm{m}^{2}$ [32], our single-unit RED results could consistently show such trends when increasing the membrane pairs, decreasing separation distance, and enlarging membrane surface area. The handy lab-scale single compartment fluidics can be extended to explore various complex RED parameters conveniently.

\section{Conclusions}

A RED power generation unit was designed, consisting of two reservoirs separated by a cation-selective Nafion membrane. Solutions of different salt concentrations flow through the reservoirs, establishing a concentration gradient across the nanoporous membrane. 
This setup generates electricity by exploiting the membrane charge-selectivity and electromigration of ions by harnessing renewable salinity gradient energy. In the present study, we analyzed the effect of concentration difference and flow rate on the RED electrical $I-V$ characteristics.

On the one hand, the inflow rate-varied over three orders of magnitudes-shows an insignificant impact on the RED electrical outputs. This may be explained by the dominance of diffusive transport over advection in the low Peclet number nature for the RED cell exploiting nanoporous CEM membrane. On the other hand, the experimental data show that both internal resistance $\left(R_{c}\right)$ and maximum power density $\left(P_{c, m}\right)$ demonstrate a power-law dependence on concentration difference, $\Delta c$. In contrast, open-circuit voltage $\left(\phi_{0}\right)$ shows a logarithmic dependence on $\Delta c$. Both the power-law and logarithmic relations (of $P_{c, m}$ and $\phi_{0}$ on $\Delta c$, respectively) found with the experimental RED using a charged membrane are consistent with previous simulation results of the RED outputs using a charged nanochannel. This implies that parallelization of bundle charged nanochannels could be a good approximation for mimicking an ion-exchange nanoporous membrane as a first-order approximation. The empirical relations of the electrical outputs depending on $\Delta c$ can be helpful for future designs of similar RED membrane cells.

In terms of applications, experimentally, when $\Delta c \gtrsim 0.2 \mathrm{M}$, the change in open-circuit voltage with $\Delta c$ was found to be negligible, implying an optimal operation for the RED membrane cell. Finally, consistent and robust renewable electricity generation with the open-circuit voltage of $\phi_{0}=0.23 \mathrm{~V}$ was produced using a Nafion membrane RED cell, with common salt solutions with $\Delta c \gtrsim 0.2 \mathrm{M}$.

Author Contributions: Conceptualization, S.C. and P.A.T.; methodology, S.C. and P.A.T.; validation, S.C. and P.A.T.; formal analysis, S.C. and P.A.T.; investigation, S.C.; resources, P.A.T.; data curation, S.C.; writing—original draft preparation, S.C.; writing—-review and editing, P.A.T.; visualization, S.C. and P.A.T.; supervision, P.A.T.; funding acquisition, P.A.T. All authors have read and agreed to the published version of the manuscript.

Funding: S.C. acknowledges the support from Alberta Innovates (AI) via a graduate student scholarship. This research was funded by the Natural Sciences and Engineering Research Council of Canada (NSERC) Discovery grant number RGPIN-2020-05511 and Canada Research Chair in Fluids and Interfaces (CRC TIER2 233147).

Institutional Review Board Statement: Not applicable.

Informed Consent Statement: Not applicable.

Data Availability Statement: Data available upon reasonable request.

Conflicts of Interest: The authors declare no conflict of interest.

\author{
Abbreviations \\ SGE Salinity gradient energy \\ RED reverse electrodialysis \\ CEM cation exchange membrane
}

The following abbreviations are used in this manuscript:

\title{
References
}

1. Jia, Z.; Wang, B.; Song, S.; Fan, Y. Blue energy: Current technologies for sustainable power generation from water salinity gradient. Renew. Sustain. Energy Rev. 2014, 31, 91-100. [CrossRef]

2. Yip, N.Y.; Brogioli, D.; Hamelers, H.V.M.; Nijmeijer, K. Salinity Gradients for Sustainable Energy: Primer, Progress, and Prospects. Environ. Sci. Technol. 2016, 50, 12072-12094. [CrossRef] [PubMed]

3. Hong, J.G.; Zhang, B.; Glabman, S.; Uzal, N.; Dou, X.; Zhang, H.; Wei, X.; Chen, Y. Potential ion exchange membranes and system performance in reverse electrodialysis for power generation: A review. J. Memb. Sci. 2015, 486, 71-88. [CrossRef]

4. Yip, N.Y.; Elimelech, M. Performance Limiting Effects in Power Generation from Salinity Gradients by Pressure Retarded Osmosis. Environ. Sci. Technol. 2011, 45, 10273-10282. [CrossRef] 
5. Brogioli, D. Extracting Renewable Energy from a Salinity Difference Using a Capacitor. Phys. Rev. Lett. 2009, $103,058501$. [CrossRef]

6. Post, J.W.; Veerman, J.; Hamelers, H.V.M.; Euverink, G.J.W.; Metz, S.J.; Nymeijer, K.; Buisman, C.J.N. Salinity-gradient power: Evaluation of pressure-retarded osmosis and reverse electrodialysis. J. Memb. Sci. 2007, 288, 218-230. [CrossRef]

7. Norman, R.S. Water Salination: A Source of Energy. Science 1974, 186, 350-352. [CrossRef]

8. Dlugolecki, P.; Nymeijer, K.; Metz, S.; Wessling, M. Current status of ion exchange membranes for power generation from salinity gradients. J. Memb. Sci. 2008, 319, 214-222. [CrossRef]

9. Dai, A.; Trenberth, K. Estimates of freshwater discharge from continents: Latitudinal and seasonal variations. J. Hydrometeorol. 2002, 3, 660-687. [CrossRef]

10. Pattle, R.E. Production of electric power by mixing fresh and salt water in the hydroelectric pile. Nature 1954, 174, 660. [CrossRef]

11. Tedesco, M.; Cipollina, A.; Tamburini, A.; Micale, G. Towards $1 \mathrm{~kW}$ power production in a reverse electrodialysis pilot plant with saline waters and concentrated brines. J. Memb. Sci. 2017, 522, 226-236. [CrossRef]

12. REDSTACK, The Netherlands. Available online: https:/ / www.redstack.nl/en (accessed on 27 October 2021).

13. Kilsgaard, B.S.; Haldrup, S.; Catalano, J.; Bentien, A. High figure of merit for electrokinetic energy conversion in Nafion membranes. J. Power Sources 2014, 247, 235-242. [CrossRef]

14. Barry, E.; McBride, S.P.; Jaeger, H.M.; Lin, X.M. Ion transport controlled by nanoparticle-functionalized membranes. Nat. Commun. 2014, 5, 5847. [CrossRef]

15. Haldrup, S.; Catalano, J.; Hinge, M.; Jensen, G.V.; Pedersen, J.S.; Bentien, A. Tailoring Membrane Nanostructure and Charge Density for High Electrokinetic Energy Conversion Efficiency. ACS Nano 2016, 10, 2415-2423. [CrossRef]

16. Feng, J.; Graf, M.; Liu, K.; Ovchinnikov, D.; Dumcenco, D.; Heiranian, M.; Nandigana, V.; Aluru, N.R.; Kis, A.; Radenovic, A. Single-layer MoS2 nanopores as nanopower generators. Nature 2016, 536, 197-200. [CrossRef]

17. Tufa, R.A.; Pawlowski, S.; Veerman, J.; Bouzek, K.; Fontananova, E.; di Profio, G.; Velizarov, S.; Goulão Crespo, J.; Nijmeijer, K.; Curcio, E. Progress and prospects in reverse electrodialysis for salinity gradient energy conversion and storage. Appl. Energy 2018, 225, 290-331. [CrossRef]

18. Fu, Y.; Guo, X.; Wang, Y.; Wang, X.; Xue, J. An atomically-thin graphene reverse electrodialysis system for efficient energy harvesting from salinity gradient. Nano Energy 2019, 57, 783-790. [CrossRef]

19. Huang, X.; Zhang, Z.; Kong, X.Y.; Sun, Y.; Zhu, C.; Liu, P.; Pang, J.; Jiang, L.; Wen, L. Engineered PES/SPES nanochannel membrane for salinity gradient power generation. Nano Energy 2019, 59, 354-362. [CrossRef]

20. Liu, X.; He, M.; Calvani, D.; Qi, H.; Gupta, K.; de Groot, H.; Sevink, G.; Buda, F.; Kaiser, U.; Schneider, G. Power generation by reverse electrodialysis in a single-layer nanoporous membrane made from core-rim polycyclic aromatic hydrocarbons. Nat. Nanotechnol. 2020, 15, 307-312. [CrossRef]

21. Li, C.; Wen, L.; Sui, X.; Cheng, Y.; Gao, L.; Jiang, L. Large-scale, robust mushroom-shaped nanochannel array membrane for ultrahigh osmotic energy conversion. Sci. Adv. 2021, 7, eabg2183. [CrossRef]

22. Mehdizadeh, S.; Kakihana, Y.; Abo, T.; Yuan, Q.; Higa, M. Power generation performance of a pilot-scale reverse electrodialysis using monovalent selective ion-exchange membranes. Membranes 2021, 11, 27. [CrossRef] [PubMed]

23. Kim, Y.; Logan, B.E. Microbial Reverse Electrodialysis Cells for Synergistically Enhanced Power Production. Environ. Sci. Technol. 2011, 45, 5834-5839. [CrossRef] [PubMed]

24. Weiner, A.M.; McGovern, R.K.; Lienhard V, J.H. A new reverse electrodialysis design strategy which significantly reduces the levelized cost of electricity. J. Memb. Sci. 2015, 493, 605-614. [CrossRef]

25. Kwon, K.; Park, B.H.; Kim, D.H.; Kim, D. Comparison of spacer-less and spacer-filled reverse electrodialysis. J. Renew. Sustain. Energy 2017, 9, 044502. [CrossRef]

26. Kang, B.; Kim, H.J.; Kim, D.K. Membrane electrode assembly for energy harvesting from salinity gradient by reverse electrodialysis. J. Memb. Sci. 2018, 550, 286-295. [CrossRef]

27. Sales, B.B.; Saakes, M.; Post, J.W.; Buisman, C.J.N.; Biesheuvel, P.M.; Hamelers, H.V.M. Direct Power Production from a Water Salinity Difference in a Membrane-Modified Supercapacitor Flow Cell. Environ. Sci. Technol. 2010, 44, 5661-5665. [CrossRef] [PubMed]

28. Tufa, R.A.; Noviello, Y.; Di Profio, G.; Macedonio, F.; Ali, A.; Drioli, E.; Fontananova, E.; Bouzek, K.; Curcio, E. Integrated membrane distillation-reverse electrodialysis system for energy-efficient seawater desalination. Appl. Energy 2019, $253,113551$. [CrossRef]

29. Cao, L.; Guo, W.; Ma, W.; Wang, L.; Xia, F.; Wang, S.; Wang, Y.; Jiang, L.; Zhu, D. Towards understanding the nanofluidic reverse electrodialysis system: well matched charge selectivity and ionic composition. Energy Environ. Sci. 2011, 4, 2259-2266. [CrossRef]

30. He, Y.; Huang, Z.; Chen, B.; Tsutsui, M.; Shui Miao, X.; Taniguchi, M. Electrokinetic Analysis of Energy Harvest from Natural Salt Gradients in Nanochannels. Sci. Rep. 2017, 7, 1-15. [CrossRef]

31. Graf, M.; Lihter, M.; Unuchek, D.; Sarathy, A.; Leburton, J.P.; Kis, A.; Radenovic, A. Light-Enhanced Blue Energy Generation Using MoS2 Nanopores. Joule 2019, 3, 1549-1564. [CrossRef]

32. Mei, Y.; Tang, C.Y. Recent developments and future perspectives of reverse electrodialysis technology: A review. Desalination 2018, 425, 156-174. [CrossRef]

33. Lee, Y.; Kim, H.J.; Kim, D.K. Power generation from concentration gradient by reverse electrodialysis in anisotropic nanoporous anodic aluminum oxide membranes. Energies 2020, 13, 904. [CrossRef] 
34. Masliyah, J.H.; Bhattacharjee, S. Electrokinetic and Colloid Transport Phenomena; John Wiley \& Sons, Ltd.: Hoboken, NJ, USA, 2005; pp. 1-707.

35. Bocquet, L.; Charlaix, E. Nanofluidics, from bulk to interfaces. Chem. Soc. Rev. 2010, 39, 1073-1095. [CrossRef]

36. Benneker, A.M.; Wood, J.A.; Tsai, P.A.; Lammertink, R.G. Observation and experimental investigation of confinement effects on ion transport and electrokinetic flows at the microscale. Sci. Rep. 2016, 6, 37236. [CrossRef]

37. Siria, A.; Bocquet, M.L.; Bocquet, L. New avenues for the large-scale harvesting of blue energy. Nat. Rev. Chem. 2017, 1. [CrossRef]

38. Fair, J.C.; Osterle, J.F. Reverse Electrodialysis in Charged Capillary Membranes. J. Chem. Phys. 1971, 54, 3307. [CrossRef]

39. Gross, R.J.; Osterle, J.F. Membrane transport characteristics of ultrafine capillaries. J. Chem. Phys. 1968, 49, 228-234. [CrossRef] [PubMed]

40. Kim, D.K. Numerical study of power generation by reverse electrodialysis in ion-selective nanochannels. J. Mech. Sci. Technol. 2011, 25, 5-10. [CrossRef]

41. Kang, B.D.; Kim, H.J.; Lee, M.G.; Kim, D.K. Numerical study on energy harvesting from concentration gradient by reverse electrodialysis in anodic alumina nanopores. Energy 2015, 86, 525-538. [CrossRef]

42. Chanda, S.; Tsai, P.A. Numerical simulation of renewable power generation using reverse electrodialysis. Energy 2019, 176, 531-543. [CrossRef]

43. Alizadeh, A.; Wang, M. Reverse electrodialysis through nanochannels with inhomogeneously charged surfaces and overlapped electric double layers. J. Colloid Interface Sci. 2018, 529, 214-223. [CrossRef]

44. Siria, A.; Poncharal, P.; Biance, A.L.; Fulcrand, R.; Blase, X.; Purcell, S.T.; Bocquet, L. Giant osmotic energy conversion measured in a single transmembrane boron nitride nanotube. Nature 2013, 494, 455-458. [CrossRef]

45. Vilà, N.; de Oliveira, P.; Walcarius, A.; Mbomekallé, I.M. pH-modulated ion transport and amplified redox response of Keggintype polyoxometalates through vertically-oriented mesoporous silica nanochannels. Electrochim. Acta 2019, 309, $209-218$. [CrossRef]

46. Xiao, K.; Jiang, L.; Antonietti, M. Ion Transport in Nanofluidic Devices for Energy Harvesting. Joule 2019, 3, 2364-2380. [CrossRef]

47. Laucirica, G.; Toimil-Molares, M.E.; Trautmann, C.; MarmisollÃ@), W.; Azzaroni, O. Nanofluidic osmotic power generatoradvanced nanoporous membranes and nanochannels for blue energy harvesting. Chem. Sci. 2021, 12, 12874-12910. [CrossRef]

48. Siwy, Z.S. Ion-Current Rectification in Nanopores and Nanotubes with Broken Symmetry. Adv. Funct. Mater. 2006, 16, 735-746. [CrossRef]

49. Karnik, R.; Duan, C.; Castelino, K.; Daiguji, H.; Majumdar, A. Rectification of ionic current in a nanofluidic diode. Nano Lett. 2007, 7, 547-551. [CrossRef] [PubMed]

50. Liu, J.; Kvetny, M.; Feng, J.; Wang, D.; Wu, B.; Brown, W.; Wang, G. Surface charge density determination of single conical nanopores based on normalized ion current rectification. Langmuir 2012, 28, 1588-1595. [CrossRef] [PubMed]

51. Zhang, Z.; Kong, X.Y.; Xiao, K.; Liu, Q.; Xie, G.; Li, P.; Ma, J.; Tian, Y.; Wen, L.; Jiang, L. Engineered Asymmetric Heterogeneous Membrane: A Concentration-Gradient-Driven Energy Harvesting Device. JACS 2015, 137, 14765-14772. [CrossRef]

52. Guo, W.; Cao, L.; Xia, J.; Nie, F.Q.; Ma, W.; Xue, J.; Song, Y.; Zhu, D.; Wang, Y.; Jiang, L. Energy Harvesting with Single-Ion-Selective Nanopores: A Concentration-Gradient-Driven Nanofluidic Power Source. Adv. Funct. Mater. 2010, 20, 1339-1344. [CrossRef]

53. Ji, J.; Kang, Q.; Zhou, Y.; Feng, Y.; Chen, X.; Yuan, J.; Guo, W.; Wei, Y.; Jiang, L. Osmotic Power Generation with Positively and Negatively Charged 2D Nanofluidic Membrane Pairs. Adv. Funct. Mater. 2017, 27, 1603623. [CrossRef]

54. Ouyang, W.; Wang, W.; Zhang, H.; Wu, W.; Li, Z. Nanofluidic crystal: a facile, high-efficiency and high-power-density scaling up scheme for energy harvesting based on nanofluidic reverse electrodialysis. Nanotechnology 2013, 24, 345401. [CrossRef] [PubMed]

55. Choi, E.; Kwon, K.; Kim, D.; Park, J. Lab on a Chip. Lab Chip 2015, 15, 168-178. [CrossRef]

56. Vermaas, D.A.; Veerman, J.; Yip, N.Y.; Elimelech, M.; Saakes, M.; Nijmeijer, K. High efficiency in energy generation from salinity gradients with reverse electrodialysis. ACS Sustain. Chem. Eng. 2013, 1, 1295-1302. [CrossRef]

57. Micari, M.; Cipollina, A.; Giacalone, F.; Kosmadakis, G.; Papapetrou, M.; Zaragoza, G.; Micale, G.; Tamburini, A. Towards the first proof of the concept of a Reverse ElectroDialysis-Membrane Distillation Heat Engine. Desalination 2019, 453, 77-88. [CrossRef]

58. Xu, T. Ion exchange membranes: State of their development and perspective. J. Memb. Sci. 2005, 263, 1-29. [CrossRef]

59. Chen, J.; Xin, W.; Chen, W.; Zhao, X.; Qian, Y.; Kong, X.Y.; Jiang, L.; Wen, L. Biomimetic Nanocomposite Membranes with Ultrahigh Ion Selectivity for Osmotic Power Conversion. ACS Cent. Sci. 2021, 7, 1486-1492. [CrossRef] [PubMed]

60. Banan Sadeghian, R.; Pantchenko, O.; Tate, D.; Shakouri, A. Miniaturized concentration cells for small-scale energy harvesting based on reverse electrodialysis. Appl. Phys. Lett. 2011, 99, 173702. [CrossRef]

61. Bentien, A.; Okada, T.; Kjelstrup, S. Evaluation of Nanoporous Polymer Membranes for Electrokinetic Energy Conversion in Power Applications. J. Phys. Chem. C 2013, 117, 1582-1588. [CrossRef]

62. Tufa, R.A.; Piallat, T.; Hnat, J.; Fontananova, E.; Paidar, M.; Chanda, D.; Curcio, E.; di Profio, G.; Bouzek, K. Salinity gradient power reverse electrodialysis: Cation exchange membrane design based on polypyrrole-chitosan composites for enhanced monovalent selectivity. Chem. Eng. J. 2020, 380, 122461. [CrossRef]

63. Catalano, J.; Bentien, A. Influence of temperature on the electrokinetic properties and power generation efficiency of Nafion ${ }^{\circledR} 117$ membranes. J. Power Sources 2014, 262, 192-200. [CrossRef]

64. Guo, Z.Y.; Ji, Z.Y.; Zhang, Y.G.; Yang, F.J.; Liu, J.; Zhao, Y.Y.; Yuan, J.S. Effect of ions (K+, Mg2+, Ca2+ and SO42-) and temperature on energy generation performance of reverse electrodialysis stack. Electrochim. Acta 2018, 290, 282-290. [CrossRef] 
65. Avci, A.H.; Sarkar, P.; Tufa, R.A.; Messana, D.; Argurio, P.; Fontananova, E.; Di Profio, G.; Curcio, E. Effect of Mg2+ ions on energy generation by Reverse Electrodialysis. J. Memb. Sci. 2016, 520, 499-506. [CrossRef]

66. Pintossi, D.; Chen, C.L.; Saakes, M.; Nijmeijer, K.; Borneman, Z. Influence of sulfate on anion exchange membranes in reverse electrodialysis. NPJ Clean Water 2020, 3, 1-10. [CrossRef]

67. Vermaas, D.A.; Veerman, J.; Saakes, M.; Nijmeijer, K. Influence of multivalent ions on renewable energy generation in reverse electrodialysis. Energy Environ. Sci. 2014, 7, 1434-1445. [CrossRef]

68. Galama, A.H.; Vermaas, D.A.; Veerman, J.; Saakes, M.; Rijnaarts, H.H.M.; Post, J.W.; Nijmeijer, K. Membrane resistance: The effect of salinity gradients over a cation exchange membrane. J. Memb. Sci. 2014, 467, 279-291. [CrossRef]

69. Balme, S.; Ma, T.; Balanzat, E.; Janot, J.M. Large osmotic energy harvesting from functionalized conical nanopore suitable for membrane applications. J. Memb. Sci. 2017, 544, 18-24. [CrossRef]

70. Moreno, J.; Grasman, S.; Van Engelen, R.; Nijmeijer, K. Upscaling Reverse Electrodialysis. Environ. Sci. Technol. 2018, 52, 10856-10863. [CrossRef] [PubMed]

71. Wang, L.; Wang, Z.; Patel, S.K.; Lin, S.; Elimelech, M. Nanopore-Based Power Generation from Salinity Gradient: Why It Is Not Viable. ACS Nano 2021, 15, 4093-4107. [CrossRef] [PubMed]

72. Kavokine, N.; Netz, R.R.; Bocquet, L. Fluids at the Nanoscale: From Continuum to Subcontinuum Transport. Annu. Rev. Fluid Mech. 2021, 53, 377-410. [CrossRef]

73. Zawodzinski, T.A.; Neeman, M.; Sillerud, L.O.; Gottesfeld, S. Determination of water diffusion coefficients in perfluorosulfonate ionomeric membranes. J. Phys. Chem. 1991, 95, 6040-6044. [CrossRef]

74. Chein, R.; Liu, B. Energy conversion from electrolyte concentration gradient using charged nano-pores. Int. J. Green Energy 2017, 13, 1400-1411. [CrossRef] 